\title{
The Study of Solution-Focused Group Counseling in Decreasing Depression among Teenage Girls
}

\author{
Leila Javanmiri ${ }^{1}$, Seyyed Ali Kimiaee ${ }^{1} \&$ Bahram Ali Ghanbari Hashem Abadi ${ }^{1}$ \\ ${ }^{1}$ Psychology, Ferdowsi university of Mashhad, Iran \\ Correspondence: Leila Javanmiri, No 16, Al 106, Nohom Streat, Markazi Avanue, 22bahman, Kermanshah, Iran. \\ Tel: 98-935-414-3937. E-mail: alma_javan@yahoo.com
}

Received: September 25, 2012

Accepted: December 3, $2012 \quad$ Online Published: February 21, 2013

doi:10.5539/ijps.v5n1p105

URL: http://dx.doi.org/10.5539/ijps.v5n1p105

\begin{abstract}
The aim of this study is to determine the effect of solution-focused approach in decreasing depression among teenage girls. Depression is one of the most common diseases in these days which have been known as mental flu. Adolescence also plays a pivotal and key role in our in which depression is very common. So it is necessary to treat this disorder in adolescence.

This research is a quasi-experimental design in which pretest-posttest design with a control group has been used. The population was all teenage girls in Sahneh; 20 girls were drawn from the population through stratified random sampling and then randomly assigned to two groups: one experimental and one control. Data were collected through Beck's depression questionnaire (BDI). Dependent variable was solution-focused therapy in which experimental group was provided with 8 -hour group counseling ( 8 sessions which took one hour). In the meantime, control group was provided with irrelevant teachings (teaching study skills) to eliminate the effect of subjects. After the sessions were wound up, BDI questionnaire was administered again among both groups. One month later, the posttest and then BDI questionnaire were conducted. After that, $t$ test and covariance were used to analyze the findings. The results showed that solution-focused group counseling is effective in decreasing depression among teenage girls and its significance level is at $\alpha=0 / 01$. In addition, the findings obtained through posttest indicated how stable the effect of therapy is. In other words, solution-focused group counseling has significantly led to decreasing depression in teenage girls.
\end{abstract}

Keywords: depression, teenagers, solution-focused therapy

\section{Introduction}

Depression is one of the leading causes of morbidity and mortality in the world today and places profound economic burden on society (Greenberg, Kessler, Birnbaum, 2003\& Lynch, Clarke, 2006). Youth depression is quite common (Kovacs, 2006) and is associated with negative long-term psychiatric and functional outcomes (Bar done, Moffitt, 1996 \& Weismann, Wok, Goldstein, 1999) such as including impairment in school, work, and interpersonal relationships, substance abuse and suicide attempts (Rubin, Both, Zahn-Waxler, 1991 and Zahn-Waxler, Dodge, Valence, 1995).

The depression is the most prevalent mental illness in present century; it's considered as the most serious illness and as Harvard University reported, it will be in the top of prevalent illnesses list by 2020. It is a mental disorder that affects one's thinking, feelings, behaviors and physical performance (Butler, 2002, cite by Aston et al, 2004).

Depression incurs nearly $12 \%$ of world's population to pay heavy expenses (Aston et al, 2004). Normally the cost which incurs by a depressed person is much more than those incurred by victims of other illnesses (Vakili et al, 2009). Economists estimated that depression incurs 43 billion dollars to the U.S.A. per year (Hunter, 2009).

According to DSM-IV, depression could be detected by 8 main features: bad mood (at least for two weeks), dissatisfaction in many activities, disorders while sleeping, significant changes in weight, lack of energy, emptiness or guilt, disorders in concentration, suicide thoughts and contemplations (Greenberg \& Watson, 2007). $15 \%$ of depressed ills die of suicide. Studies show that 1,000,000 people die of suicide in the world per year; in other words, one per 30 seconds (Hunter, 2009).

Studies have proved that kids and teenagers suffer from depression as adults do and these disorders affect their performance and whole lives (Neshatdust, 2007). Teenagers pass the childhood towards adulthood; many of 
them experience personal and family problems during this period (Lindsey et al, 2000 cited by Kameli, 2009). Being informed of revolutions in this period can help us to behave them as well as possible and to plan suitable manners for encouraging them to social behaviors, and plan educational programs which are motivating and challenge them.

Solution-Focused Brief Therapy (SFBT) was the result of a social aid worker's efforts namely Steve De Shazer and his co-workers in MRI family health center located in Milwaukee (Goldenberg \& Goldenberg, 2000). This attitude focuses on difficult exceptions; from this point of view, changes and revolutions are inevitable affairs; especially possible positive changes. So in this kind of treatment, the focus is on affairs which have potential of a change rather than on difficult aspects which cannot be changed (Hanlon, O \& Weiner-Davis, M 1989 cited by Nazari \& Nawabinijad, 2006, Nazari \& Goli, 2007). So this treatment is well-known as Hope Consultation (Nunnlly, 1993).

Although this model is based on theory and educable by special techniques, it's important to know the base of this treatment is a universal insight namely a method to think and to be, not a set of clinical treatments (Lipchik, 1994). As it is self-explanatory, this attitude focuses on solutions which are efficient for patients. It is the revised model of post-structuralism that is an effective attitude that is not based on do's and accentuates on using language in social structure of Reality (look at Hoyt, 1994a , 1996 , 1998, 2000, 2004; Macknimi \& Gregen, 1992; Miller, 1997 cited by Gurman, 2008). This treatment signifies the identity strength and is based on hypotheses according to which patients have ability, creativity and sometimes facilitating skills and can change the prospects and opinions so that they could provide new options to experience and interact with (Gurman, 2008).

Solution-Focused Brief Therapy (SFBT) appeared as a short-term psychiatry method since 15 or 20 years ago and proved that has dominated some parts of problem-based attitudes in mental clinics (Osborn, C.J \& Johansson. G. A, 2001).

This attitude is an interruption based on forces that is made of trust in referred ones and is important to make references and enthusiasm for patients; because they know better about their illness and are qualified to make solutions to solve their problems (Miller and De Shazer, S. 2000). It is believed in this attitude that a linear or direct method which could solve the problem is not enough. In this method, treatment goals are positively formulized: for example instead of "squabble omission", they use "ability to solve the problem by free discussions" (Saeedi et al, 1385, cited by Ghamari, 2009). De Shazer (1991) stated that the ways people use are trouble-making; not the trouble itself. So the most concentration is on solutions and acceptability, and the goal is to choose those concepts that would lead to change (Anderson, 2001; quoted from Sexton et al, 2003). According to its fundamentalists, the important feature of this attitude is its short-term and optimistic nature (quoted from Gitipasand et al, 2009). The solution-focused opinion has a non-pathological attitude towards the referred ones and helps patients to find solutions for their current problems. This attitude emphasizes on here, now, and also the future. The studies show that this attitude may lead to desirable results and even works well in urgent situations (Lee My, 1997).

According to the theories and findings of mentioned research, it can be concluded that the solution-focused consultation attitude (considering its being optimistic) is an effective attitude that can be used in schools and for teenagers. Also according to the researches carried out in Iran, this attitude has not been applied for teenagers' depression yet. So due to its importance, this study would find the answer of this question: "Could the solution-focused consultation attitude be useful to reduce the depression among teenagers?"

\section{Method}

The main hypothesis of the present research is that the grouped consultation contingent upon solution-focused therapy can meaningfully reduce the symptoms of depression in teenage girls of the experimental group in comparison with the control group. Research was done under semi-experimental design with two groups (experimental and control) taking pre-test and post-test.

In this study, the statistic community was all teenage girls (between 15 and 18) of Sahne city in Kermanshah province that have been examined by Beck Depression questionnaire and take no medicines or medical-psychiatric treatments now. Cases include 20 girls selected by multistage cluster sampling method and randomly divided into two groups (experimental and sham control). Reading skills were taught to the teenagers of sham control group. The conditions of entering to experimental or sham control groups were: 1.Lack of taking any medical or psychiatric treatment 2.Lack of insanity 3.Meeting a clinical interview based on DSM-IV-2 principles and aged 15 to 18 . 
Research material was Beck Depression questionnaire, second edition (Beck, Steer \& Brown, 1996; cited by Fata, 2003). In comparison with its first edition, the second one has more consistency with the DSM-IV. It covers all elements of depression according to depression theories. Like the first edition, this questionnaire consists of 21 articles, asking the responders to grade the intensity of symptoms from 1 to 3 . It can be used only for up-13 year population and following points have been considered for it: 0-13 no or least depression; 14-19 slight depression; 20-28 moderate depression; 29-63 extreme depression (Growth-Marat, 1384). Suitable validity and stability have been reported for the first edition of Beck Depression Questionnaire (Growth-Marat, 2005).

In an Iranian sample, the alpha coefficient, the correlation coefficient of the two halves, the retest coefficient in an interval of a week and its correlation with the first questioner of the first edition were reported $0.91,0.89,0.94$, 0.93 respectively (Fata, 2003).

\section{Results}

The results of Beck Depression Questionnaire were from 20 teenagers, 10 of them in experimental group and 10 in control group. Their distribution was equal.

Table 1. Total results of age-range of cases divided by groups and descriptive statistics scales

\begin{tabular}{lllllll}
\hline Statistics & \multicolumn{2}{c}{15 -year } & \multicolumn{2}{c}{ 16-year } & \multicolumn{2}{c}{17 -year } \\
Groups & Frequency & Percentage & Frequency & Percentage & Frequency & Percentage \\
\hline Experimental & 2 & 20 & 3 & 30 & 5 & 50 \\
Control & - & - & 8 & 80 & 2 & 20 \\
Total & 2 & 10 & 11 & 55 & 7 & 35 \\
\hline
\end{tabular}

As it can be seen in table 1, the frequency of age-variety is nearly same in both groups.

The Kalmogroof-Smirnoof test was used to show whether scores had normaally been distributed in both experimental and control groups. Results showed that the distribution of scores in different levels for depression scale is normal.

Table 2. Results of comparing scores of Beck's depression scale in pre-test for cases using the T-test

\begin{tabular}{lllllll}
\hline Variant & Group, crowd & Mean & SD & DF & T-value & P-value \\
\hline $\begin{array}{l}\text { Beck's } \\
\text { depression } \\
\text { scale }\end{array}$ & Experimental, 10 & 21.7 & 4.92 & 18 & 0.477 & 0.639 \\
\hline
\end{tabular}

According to the table 2, results of the T-test showed that the difference between averages of groups in Beck's depression scale on alpha level $=0.05$ is not meaningful. In other words, no statistic difference in Beck's depression scale was found between the two groups during the pre-test level.

Table 3. Results of comparing scores of Beck's depression scale in post-test for cases using the T-test

\begin{tabular}{cccccccc}
\hline Variant & Group, crowd & Mean & SD & DF & T-value & & P-value \\
\hline Beck's & Experimental, 10 & 9.7 & 3.05 & & & \\
$\begin{array}{c}\text { depression } \\
\text { scale }\end{array}$ & Control, 10 & 19.8 & 4.66 & 18 & 5.73 & 0.0001 & \\
\hline
\end{tabular}

According to the table 3, the results of T-test showed that the difference between averages of groups in Beck's depression scale in alpha level $=0.01$ is statically significant. In other words, in the post-test level, there is a statically meaningful difference between the groups. Therefore the hypothesis of research which was the effects of solution-focused grouped counseling on reducing depression symptoms in teenage girls is confirmed.

The loon test was used to show the consistency of variances in both groups. Results showed that the Lon test was 
not meaningful; hence the theory of equality of variances was observed $(\mathrm{P}>0.5)$.

Table 4. Results of analyzing covariance of hypothesis of the research related to significant of the difference between scores of experimental \& sham control group in Beck's depression scale

\begin{tabular}{|c|c|c|c|c|c|c|c|c|c|}
\hline $\begin{array}{l}\text { Diffraction } \\
\text { Source }\end{array}$ & $\begin{array}{l}\text { Sum } \\
\text { Squares }\end{array}$ & of & $\begin{array}{l}\text { Level } \\
\text { Freedom }\end{array}$ & of & $\begin{array}{l}\text { Mean } \\
\text { Squares }\end{array}$ & of & $\mathrm{F}$ & $\begin{array}{l}\text { Meaningfulness } \\
\text { Level }\end{array}$ & $\begin{array}{l}\text { Detected } \\
\text { Power }\end{array}$ \\
\hline Post-test & 510.05 & & 1 & & 510.05 & & 32.824 & 0.0001 & 0.646 \\
\hline Group & 510.05 & & 1 & & 510.05 & & 32.824 & 0.0001 & 0.626 \\
\hline Error & 279.7 & & 18 & & 15.539 & & - & - & - \\
\hline Total & 5141 & & 20 & & - & & - & - & - \\
\hline
\end{tabular}

The table 4 shows that the hypothesis of this research is confirmed and average of reduced scores means solution-focused grouped counseling has positive effects on reducing depression symptoms in teenage girls. In other words, after reduction of pre-test scores, there is a significant effect of elements between variants $(\mathrm{F}(1,18)$ $=32 / 824, \mathrm{P}<0.001)$.

\subsection{Findings of Follow-Up Test}

Table 5. Results of comparing scores of Beck's depression scale in follow-up test for cases using the T-test

\begin{tabular}{lllllll}
\hline Variant & Group, crowd & Mean & SD & DF & T-value & P-value \\
\hline $\begin{array}{l}\text { Beck's } \\
\text { depression } \\
\text { scale }\end{array}$ & Experimental, 10 & 10 & 1.94 & 18 & 6.173 & 0.0001 \\
\hline
\end{tabular}

According to the table 5, the results of T-test showed that the difference between averages of groups in Beck's depression scale in alpha level $=0.01$ is statically meaningful. In other words, in the follow-up test level, there is a statically meaningful difference between the groups. Therefore the hypothesis of research which was the effects of solution-focused grouped consultation on reducing depression symptoms in teenage girls is confirmed. Also the results prove the permanence of treatment effects.

Table 6. Results of analyzing covariance of hypothesis of the research related to meaningfulness of the difference between scores of experimental \& control group in Beck's depression scale

\begin{tabular}{|c|c|c|c|c|c|c|c|}
\hline $\begin{array}{l}\text { Diffraction } \\
\text { Source }\end{array}$ & $\begin{array}{l}\text { Sum } \\
\text { Squares }\end{array}$ & of & $\begin{array}{l}\text { Level of } \\
\text { Freedom }\end{array}$ & $\begin{array}{l}\text { Mean } \\
\text { Squares }\end{array}$ & of & $\begin{array}{l}\text { Meaningfulness } \\
\text { Level }\end{array}$ & $\begin{array}{l}\text { Detected } \\
\text { Power }\end{array}$ \\
\hline Post-test & 510.05 & & 1 & 510.05 & 38.111 & 0.0001 & 0.679 \\
\hline Group & 510.05 & & 1 & 510.05 & 38.111 & 0.0001 & 0.661 \\
\hline Error & 240.9 & & 18 & 13.383 & - & - & - \\
\hline Total & 5281 & & 20 & - & - & - & - \\
\hline
\end{tabular}

The results of table 6 shows that the hypothesis of this research is confirmed and in follow-up test, the average of reduced scores means solution-focused grouped consultation has positive effects on reducing depression symptoms in teenage girls. In other words, after reduction of pre-test scores, there is a meaningful effect of elements between variants of groups $\left(\mathrm{F}_{(1,18)}=32 / 824, \mathrm{P}<0.001\right)$.

\section{Discussion}

The main hypothesis of this research is: solution-focused grouped consultation meaningfully reduces depression symptoms of teenage girls in experimental group in comparison with control group. 
According to this study's findings, the main hypothesis was confirmed $(\mathrm{P}<0.001)$ which shows solution-focused treatment could reduce the depression in experimental group than control group.

Also results of the follow-up test showed the permanence of (positive) effects of this treatment. Findings of this research match the findings of Sandstorm (1993, cited by Nazari, 2004) who studied depression among the college students; this shows that solution-made treatment helps people to change their opinions about life and future. This research was done in groups during an 8-hour meeting with teenage girls that demonstrated the potentials and abilities of members. Most of depressed people bear the intra-mental problems. The solution-focused treatment focuses on individuals and changing their opinions. Therefore as the results proved, using this attitude can help reducing depression among people.

Results of the present research match the study of Lafontaine \& Garner (1996, cited by Nazari, 2004) who showed the solution-focused therapy affected kids \& consultants in schools. Also, Ross (2006, cited by Sadeghifard, 2009) examined solution-focused therapy on teenagers during 24 months and found out that after first month, clinical levels of mental pathology had been meaningfully improved.

Also the SFBT attitude was used in Kim \& Franklin's research (2007-08) in schools and its focus was on self-esteem, students' behaviors and the results of their educational advancement that in all three cases had positive \& meaningful results (Kim \& Franklin, 2008).

Reviewing literature of solution-focused therapy shows this kind of treatment has been applied in different situations and for many patients and always has had useful results. It might be caused because this therapy is impossible to judge, non-encountering, apprehensive and co-operative; it focuses on now, future, difficult exceptions, positive points and abilities of patients and respects their aims and uses its inner resources and special knowledge to help them fulfill these aims. In this study, positive features of this therapy have been used to make positive changes in members. So having regard to its usefulness, consultants are suggested to use this therapy, even in schools.

\section{Conclusion}

Despite the fact that so many efforts and studies are done to introduce new therapy options for the depression (medical or psychiatric), we still are facing high rate of depression. This proves the insufficiency of current therapies and obvious need for more useful \& brief treatments. This study was aimed to reduce depression symptoms in teenage girls using SFBT by groups. Teenagers tend to participate in groups and easily accept its negative or positive effects.

Patients learn to encourage each other and this is one of the main points of change. It seems that reduction of symptoms of depression among teenagers is caused by change in their opinions and some of their behaviors. Solution-focused consultation does not pay attention to the cause of problem; but this does not mean it does not pay attention to the depth of problems. In this research the main hypotheses of SFBT was confirmed and it was concluded that members can find solutions to solve their problems by focusing on their capabilities. De Shazer (1991; cited by Nazari, 2004) reported the efficiency of SFBT from $72 \%$ to $80 \%$. In present study, this efficiency was evaluated and confirmed, too.

An important element which affected the success of consultant-according to the teenagers' depression status-was the secrecy of affairs in therapy group meetings; because this trust was given to the members from the first session that their information would be a secret forever. Group consultation in schools not only reduced the teenagers' depression but also caused more performance and efficiency for educational system, increase in educational advancement, and decrease in educational slump of case students group. The background of different researches shows that the solution-focused therapy reduces the symptoms of depression.

Russ (2006, cited by Sadeqifard) used a solution-based treatment for teenagers during 24 months and found out that after one month, the clinical levels of mental pathology has meaningfully improved.

Another experiment, named "the effects of short-term solution-based treatment on 8-year aggressive kids", was carried out and its results showed a meaningful decrease in aggressive behaviors of them (Connolly et al, 2003; cited by Sadeqifard, 2009).

Also through another research, Seagram (1997) studied the efficiency of SFBT for improving views, behaviors, thinking methods and social behaviors of teenager criminals in a control center. The studied cases were 40 teenagers that were classified according to the given order, put into two groups of experimental \& control. After 10 sessions of treatment, the results match the hypotheses of solution-based view (Nazari, 2004).

In present paper, the main hypotheses of solution-based treatment were confirmed and it was specified that 
members of group could find a solution for problems focusing on their abilities. De Shazer (1991; cited by Nazari, 2004) reported the effectiveness of solution-based treatment to be between $72 \%$ to $80 \%$. That was also confirmed in present study.

The experience of group-work with the teenagers showed that this treatment could be really applied for them since it gives them complete freedom to decide for their future and destiny. The teenagers need to find and perceive themselves and their own abilities. The solution-based treatment considers this right for them and reveals their abilities in facing different affairs.

Another important element which helped the confirmation of the main hypothesis of this research was working with the patients in groups. Through grouping, teenagers learned to trust others and it was determined that one of the main reasons of depression among members was that they did not trust the others and were not comprehended by their families \& friends. So the members found what they needed in these groups. Also they learned how to be comprehended by the other people having good relationships with them.

Reviewing present research, it can be concluded that the SFBT attitude can be effective in depression treatment. Whereas depression is one of the most prevalent mental disorders and unfortunately number of such patients is growing, this research aimed to take the first steps of using SFBT in order to encourage other researchers and consultants to use this treatment.

\section{References}

Bardone, A. M., Moffitt, T., \& Caspi, A. (1998). Adult physical health outcomes of adolescent girls with conduct disorder, depression and anxiety. $J$ Am Acad Child Adolescent Psychiatry, 37, 594-601. http://dx.doi.org/10.1097/00004583-199806000-00009

Bardone, A. M., Moffitt, T., Caspi A., et al. (1996). Adult mental health and social outcomes of adolescent girls with depression and conduct disorder. Dev Psychopathic, 8, 811-829. http://dx.doi.org/10.1017/S0954579400007446

Fata, L. (2003). Structures signifying exciting situations and cognitive process of excitement information: comparing two conceptual frameworks. A clinical P.H.D thesis. Tehran psychology institution.

Ghamari, M. (2009). Studying the effects of solution-focused consultation on reducing the different marriage disputes between couples who both work. Khanevadepajuhi journal, 19, 349-361.

Gitipasand, Z., Ariyan, K., \& Karami, A. (2009). Effects of solution-focused therapy on parent-child disputes in teenage girls. Tazeha va Pajuhesh haye Moshavereh journal, 27, 63-80.

Greenberg, L. S., \& Watson, J. C. (2007). Emotion-Focused Therapy for Depression. Washington, DC: American Psychological Association Press.

Greenberg, P. E., Kessler, R., \& Birnbaum, H. (2003). The economic burden of depression in the United States: how did it change between 1990 and 2000? J Cline Psychiatry, 64, 1465-1475. http://dx.doi.org/10.4088/JCP.v64n1211

Growth-Marat, G. (2005). A guideline of psychology for clinical psychologists, psychiatrists and consultants. Translated by Sharifi \& Nikkhoo (Eds.). Tehran: Sokhan publishers.

Gurman, Alan. S. (2008). Clinical handbook of couple therapy (4th ed). New York, London: The Guielford press.

Harnish, J. D., Dodge, K. A., \& Valente, E. (1995). Mother-child interaction quality as a partial mediator of the roles of maternal depressive symptomatology and socioeconomic status in the development of child behavior problems. Child Dev, 66, 739-753.

Hunter, D. C. (2009). The Evolution of Approaches to Depression: From Paradigm Shifts to Social Contexts. Ph.D. Dissertation, Faculty of the Chicago School of Professional Psychology.

Kameli, Z. (2009). Studying effectiveness of design-focused group treatment in reducing early poor designs for teenage girls who have lost their parents or have disqualified parents. A M.A thesis. Firdausi University of Mashhad.

Kelly, M. S., Kim, J. S., \& Franklin, C. (2008). Solution-focused brief therapy in schools: A 360-degree view of the research and practice principles. New York: oxford university press. http://dx.doi.org/10.1093/acprof:oso/9780195366297.001.0001

Kovacs, M. (2006). Next steps for research on child and adolescent depression prevention. Am J Prev Med, 31, 
184-185. http://dx.doi.org/10.1016/j.amepre.2006.07.008

Lee M. Y. (1997). Study of solution-focused brief family therapy: Outcoms and issues. American journal of family therapy, 1-17.

Lipchik, E. (1994). The rush to be brief. Family therapy Networker, 18(2), 34-39.

Lynch, F., \& Clarke, G. (2006). Estimating the economic burden of depression in children and adolescents. Am J Prev Med, 31, 143-151. http://dx.doi.org/10.1016/j.amepre.2006.07.001

Nazari, A. (2004). Studying and comparing the effects of relationship enrichment plan and solution-focused consultation on marriage satisfaction of couples who both work. A PhD thesis. Tehran's Tarbiyat Muallem University.

Nazari, A., \& Goli, M. (2007). The effects of solution-focused psychiatry on marriage satisfaction of couples who both work. Danesh \& Tandorosti Journal, 4.

Nazari, A., \& Nawabinijad, S. H. (2006). Studying effects of solution-focused consultant on marriage satisfaction of couples who both work. Tazeha va Pajuhesh haye Moshavereh journal, 20, 53-80.

Neshatdust, H. (2007). Teenagers' depression and individual \& family related elements. Pajuhesh Dar Salamate Ravanshenakhti Journa, 3, 5-28.

Numbly, T. (1993). Solution-focused therapy. In R. A. Well \& V. J., Giannetti (Eds.), Casebook of the brief psychotherapies (pp. 271-286). New York. Plenum.

Osborn, C. J., \& Johnson, G. A. (2001). Development and validation of the theoretical orientation scale for clinicians: Reflecting Solution-focuced Principles. Journal of Psychology Assessment, 8(3), 301-313. http://dx.doi.org/10.1177/107319110100800306

Rubin, K. H., Both, L., Zahn-Waxler. et al. (1991). Dyadic play behaviors of children of well and depressed mothers. Dev Psychopathol, 3, 243-251. http://dx.doi.org/10.1017/S0954579400005289

Stun, T. B., Ayes- Mateo. J. L., Chatter, S., Matchers, C., \& Murray, C. J. (2004). Global burden of depressive disorders in the year 2000. British Journal of Psychiatry, 184, 386-392. http://dx.doi.org/10.1192/bjp.184.5.386

Vakili, M., Islamie Farsani, Sh., Hosseini, S. M., \& Dehqanie Tafti, M. (2009). Studying the prevalence of depression and its related elements in truck drivers of Yazd province. Salamate Kare Iran, 6, 66-73.

Weissman, M. M., Wolk, S., Goldstein, R. B., et al. (1999). Depressed adolescents grown up. JAMA, 17, 7-13. 